\title{
Synthesis and in Silico Studies of a Benzenesulfonyl Curcumin Analogue as a New Anti Dengue Virus Type 2 (DEN2) NS2B/NS3
}

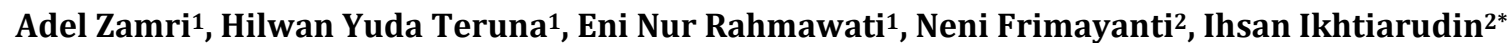

1. Department of Chemistry, Faculty Mathematics and Natural Science, Universitas Riau, Jalan H.R. Subrantas KM. 12.5 Pekanbaru, 28293, Indonesia

2. Department of Pharmacy, Sekolah Tinggi Ilmu Farmasi Riau, Jalan Kamboja, Pekanbaru, 28293, Indonesia

\begin{tabular}{|c|c|}
\hline Info Article & ABSTRACT \\
\hline Submitted: $27-02-2019$ & Curcumin has been reported can interact with multiple molecular \\
\hline Revised: 28-03-2019 & targets involved in a large variety of diseases. Accumulated evidence \\
\hline Accepted: 09-04-2019 & $\begin{array}{l}\text { indicated curcumin plays an inhibitory role against infection of numerous } \\
\text { viruses. Some studies have been reported that curcumin can interfere the }\end{array}$ \\
\hline${ }^{*}$ Corresponding author & infection processes of dengue virus. In this work, a benzenesulfonyl curcumin, \\
\hline Ihsan ikhtiarudin & $(3 E, 5 E)-3,5$-bis $(4-$ methoxybenzylidene $)-1$-(phenylsulfonyl) piperidin-4-one \\
\hline $\begin{array}{l}\text { Email: } \\
\text { ihsanikhtiarudin@stifar- } \\
\text { riau.ac.id }\end{array}$ & $\begin{array}{l}\text { of compound } 2 \text { has been established based on the interpretation of spectral } \\
\text { data include UV, FT-IR, MS/MS, }{ }^{1} \mathrm{H} \text { and }{ }^{13} \mathrm{C} \text { NMR. Then, the in silico studies } \\
\text { have been also performed to predict the potency of compound } 2 \text { as inhibitor } \\
\text { for dengue virus Type } 2 \text { (DEN 2) NS2B/NS3 protease. The in silico studies } \\
\text { showed that compound } 2 \text { has hydrogen bonding with His } 51 \text { residue, and } \\
\text { amazingly that the other catalytic triad such as Asp } 75 \text { and Ser } 135 \text { were also } \\
\text { showed interactions with the ligand. It is presumably that this compound } \\
\text { showed very good activity against DEN2 and can be developed as a new } \\
\text { inhibitor for dengue viruses. }\end{array}$ \\
\hline & Dengue virus, Molecular docking, Molecular dynamic. \\
\hline
\end{tabular}

\section{INTRODUCTION}

Dengue is the most rapidly spreading disease caused by a mosquito-borne virus in the word. It is a serious re-emerging infection disease that is endemic in over 100 countries (Morens \& Fauci, 2008). The World Health Organization (WHO) has considered dengue as a major global public health challenge in the tropic and subtropic nations. Between 1960 and 2010, dengue has seen a 30-fold upsurge worldwide, due to the increase of population growth rate, global warming, unplanned urbanization, inefficient mosquito control, frequent air travel, and lack of health care facilities (Guzman et al., 2010).

There are four serotypes of dengue virus (DEN1, DEN2, DEN3 and DEN4), with dengue virus type 2 (DEN2) being the most prevalent (Frimayanti et al., 2011). A number of studies have already revealed that the non-structural 3 (NS3) serine protease is required for the maturation of the viral polyprotein. The binding of the NS3 serine protease to an NS2B cofactor will form NS2B-NS3 protease complex (Chambers et al., 1993) which is required to cleave the viral precursor proteins that is required for DEN2 viral replication (Falgout et al., 1991). Thus, it is a promising target for the development of dengue antiviral drugs (Sampath and Padmanabhan, 2009). There are two potential targets for dengue virus NS2B/NS3 protease. First, by targeting the active site of protease and the second is by blocking the association of NS3 protease with its protein cofactor NS2B (Power and Setzer, 2016).

Curcumin has been reported can interact with multiple molecular targets involved in a large variety of diseases (Kumar et al., 2017). Accumulated evidence indicated curcumin plays an inhibitory role against infection of numerous viruses (Mathew \& Hsu, 2018). Some studies have been reported that curcumin can disrupt the infection processes of dengue virus (Padilla-S et al., 2014). In this work, we reported the synthesis of a benzenesulfonyl curcumin analogue (compound 2) under reflux. Then, the molecular docking study and molecular dynamic (MD) simulation were also performed to predict the potency of compound 2 as inhibitor for dengue virus NS2B/NS3 protease. 


\section{MATERIAL AND METHODS}

The materials were used in this work are mentioned as follow 4-piperidone, 4-methoxybenzaldehyde, benzenesulfonyl chloride, sodium hydroxide, cesium carbonate and some organic solvents, such as ethanol, acetonitrile, $n$-hexane and methanol were produced by Merck or SigmaAldrich. Melting point was determined on a FisherJohns apparatus (Fisher Scientific, Waltham, MA, USA) (uncorr). TLC Analysis was carried out using $\mathrm{GF}_{254}$ (Merck Millipore, Darmstadt, Germany) under UV Lamp 254/366nm (Camag TM, Camag Chemie-Erzeugnisse and Adsorptionstechnik AG, Muttenz, Switzerland). UV spectrum was recorded on Genesys ${ }^{\mathrm{TM}}$ 10S UV-Visible spectrophotometer (Thermo Scientific ${ }^{\mathrm{TM}}$, Waltham, MA, USA). FT-IR spectrum was recorded in $\mathrm{KBr}$ powder on a Shimadzu ${ }^{\circledR}$ FT-IR Prestige-21 spectrophotometer (Shimadzu Corporation, Kyoto, Japan).Massspectrum was recorded on LC-MS/MS +ESI (Agilent Technologies 6550 iFunnel Q-TOF LC/MS). ${ }^{1} \mathrm{H}$ and ${ }^{13} \mathrm{C}-\mathrm{NMR}$ spectral data were recorded on an Agilent ${ }^{\circledR}$ (Agilent Technologies, Santa Clara, CA, USA) at $500 \mathrm{MHz}$ and $125 \mathrm{MHz}$, respectively.

\section{Synthesis of $(3 E, 5 E)-3,5-b i s(4-m e t h o x y$ benzyli- dene)piperidin-4-one (1)}

The synthesis of compound 1 has been carried out by modifying the previous method (Eryanti et al., 2014). 4-piperidone (5mmol) and 4methoxybenzaldehyde $(10 \mathrm{mmol})$ were dissolved in absolute ethanol $(20 \mathrm{~mL})$. The $\mathrm{KOH}$ solution $(10 \%$, $10 \mathrm{~mL}$ ) was added drop by drop into the solution. Then, the mixture was refluxed at $80^{\circ} \mathrm{C}$. The reaction was monitored every $30 \mathrm{~min}$ by TLC. After the reaction was completed, the mixture was cooled in ice bath and the precipitate was filtered in vacuo, washed by aqua DM and $n$-hexane and dried in a desiccator. Then, the solid crude product was recrystallized in methanol to afford pure compound 1.

Synthesis of (3E,5E)-3,5-bis(4-methoxybenzylidene)-1-(phenyl sulfonyl)piperidin-4-one (2)

Compound $\mathbf{1}$ (1 mmol) and cesium carbonate (1.5mmol) were dissolved in acetonitrile $(20 \mathrm{~mL})$. Benzenesulfonyl chloride ( $1 \mathrm{mmol}$ ) was added drop by drop into the solution. Then, the mixture was refluxed at $80^{\circ} \mathrm{C}$ for $12 \mathrm{~h}$. The reaction was monitored every $2 \mathrm{~h}$ by TLC. After the reaction was completed, the solvent was evaporated by vacuum rotary evaporator. Then, the solid was dissolved in water and extracted with ethyl acetate (1:1). The ethyl acetate layer was collected and the solvent was evaporated by vacuum rotary evaporator to afford the solid crude product. The crude product was washed by $\mathrm{NaHCO}_{3}$ and aqua DM and recrystallized in methanol to afford a pure compound 2 .

Compound 2 was obtained as a yellow solid in $88 \%$ yield. The melting point was recorded at $210-212^{\circ} \mathrm{C}$ (uncorr). The HPLC chromatogram showed a single peak at $t_{R}=17.4 \mathrm{~min}$. The UV spectra in EtOH showed $\lambda_{\max }(\mathrm{nm})$ at 243 and 365. The FT-IR spectra in $\mathrm{KBr}$ powder showed the absorption bands $\left(\mathrm{cm}^{-1}\right)$ at 3078, 3000, 2907, 2838, $1674,1599,1508,1444,1351,1171,700$. The mass of 2 in MS/MS spectra (+ESI) was found as $\left[\mathrm{M}+\mathrm{H}^{+}\right]$ $\left(\mathrm{C}_{27} \mathrm{H}_{26} \mathrm{NO}_{5} \mathrm{~S}\right)$ at $m / z=476.1543$ and 476.1515 . The ${ }^{1} \mathrm{H}$ NMR spectra was recorded in DMSO-d 6 (500MHz): $7.68(\mathrm{t}, 1 \mathrm{H}, J=6.5 \mathrm{~Hz}), 7.54-7.56(\mathrm{~m}, 4 \mathrm{H})$, $7.50(\mathrm{~s}, 2 \mathrm{H}), 7.45(\mathrm{~d}, 4 \mathrm{H}, J=8.2 \mathrm{~Hz}), 7.09$ (d, 4H, J= $8.1 \mathrm{~Hz}), 4.61(\mathrm{~s}, 4 \mathrm{H}), 3.84(\mathrm{~s}, 6 \mathrm{H})$. The ${ }^{13} \mathrm{C}$ NMR spectra was recorded in DMSO-d 6 (125 MHz): $184.27,160.92,137.83,137.26,133.93,132.99$, 129.84, 128.86, 127.61, 127.09, 114.99, 55.85, 47.25 .

\section{Molecular docking study and molecular dynamic simulation}

The initial structure of the ligand is needed to obtain, it were optimized using density functional theory (DFT) at the B3LYP/6-311G level using Gaussian 09 software package. Docking of compound 2 was performed using Autodock software package (Jasril et al., 2017). Protein was downloaded from protein database with PDB ID: 2FOM. The rigid protein and flexible ligand was prepared using Autodock tools 1.5.6. software package. The polar and nonpolar hydrogen atom were then individually added and merged to the protein structure. Kollman charges and solvation parameters were determined. Gasteiger charges were added to the minimized ligand structures, and all bonds were made rotatable and flexible by allowing the detection of root torsion. A grid box of the protein structure was then generated using Autogrid 4 software with default atom types (carbon, hydrogen, oxygen and nitrogen), grid spacing of $0.41 \AA$, dimensions of $126 \times 126 \times 126$ points along the $\mathrm{x}, \mathrm{y}$ and $\mathrm{z}$ axes and centered on the protein for the docking. Molecular dynamic simulation was performed for compound 2 and panduratin A was used as positive control (Frimayanti, et al., 2011) using the program NAMD (NAnoscale Molecular Dynamics program; v 2.9) 
(Nelson et al., 1996), and all files were generated using visual MDs (VMD) (Humphrey et al., 1996). The protein was solvated with a TIP3P water box with a $2.5 \AA$ layer of water for each direction of the coordinate structure, and a CHARMM Chemistry at HARvard Macromolecular Mechanics) was used as a force field. Generaly, the ligands was remained stably in the binding pocket through out 100ps MD simulation. The MD simulation was running with the following parameters, the time step of 10 femtosec/step, dcdfreq of 1000 steps/trajectory snapshot and with total 1000 run step. The MD was performed until the simulation reach the equilibrium or steady state.

\section{RESULT AND DISCUSSION}

The synthesis of compound $\mathbf{2}$ was conducted under reflux by two steps of reaction. The first step is synthesis of curcumin analogue via Claisen-Schmidt condensation and the second step is synthesis of synthesis of benzenesulfonyl curcumin via nucleophilic substitution (Figure 1).

The UV spectra of compound 2 was recorded in ethanol and showed the $\lambda_{\max }(\mathrm{nm})$ at 243 and 365 . The absorptions indicated the presence of conjugated of double bonds in the aromatic rings of compound 2. The FT-IR spectra showed the absorption bands $\left(\mathrm{cm}^{-1}\right)$ at 3078, 3000, and 1599 . These three absorptions respectively were due to the presence of asymmetrical $\mathrm{C}-\mathrm{H}$, symmetrical $\mathrm{C}-\mathrm{H}$ and $\mathrm{C}=\mathrm{C}$ vibration in the aromatic phenyl rings of compound 2. The absorption bands at 2907, 2838 and 1171 respectively were due to the presence of asymmetrical $\mathrm{C}-\mathrm{H}$ vibration, symmetrical $\mathrm{C}-\mathrm{H}$ vibration and $\mathrm{C}-\mathrm{O}$ vibration in both methoxy groups. The absorption band at 1674 indicated the presence of the conjugated carbonyl group and the absorption bands at 1444 and 1351 were due to the presence of $S=0$ vibration in sulfonyl group. In addition, the MS/MS spectra also showed the appropriate mass for 2 .

The ${ }^{1} \mathrm{H}$ and ${ }^{13} \mathrm{C}$ NMR spectra (Figure 2 and 3 ) also showed the appropriate chemical environment for protons and carbons of compound 2 . The ${ }^{1} \mathrm{H}$ NMR spectra showed a singlet signal $(6 \mathrm{H})$ at $\delta$ (ppm) 3.84. This signal was due to the presence of the aliphatic protons in two methoxy groups. Another aliphatic proton signal $(4 \mathrm{H})$ was appeared at $\delta 4.61$. This signal was due to the presence of the methylene protons in the heterocyclic ring of piperidin-4-one. The aromatic proton signals of three phenyl ring were appeared at $\delta$ 7.68-7.09. The triplet signal at $\delta 7.68$ and multiplet signals at $\delta$
7.54-7.56 were due to the presence of the aromatic protons in benzenesulfonyl moiety, whereas two doublet signals at $\delta 7.45(4 \mathrm{H})$ and $7.09(4 \mathrm{H})$ were due to the presence of the aromatic protons in both $p$-methoxyphenyl rings. The singlet signal $(2 \mathrm{H})$ at $\delta 7.50$ was due to the presence of $\beta$ protons in the unsaturated $\alpha, \beta$ carbonyl system of compound 2 .

The ${ }^{13} \mathrm{C}$ NMR spectra showed aliphatic carbon signals at $\delta 55.85$ and 47.25. These two signals due to the two carbons in two methoxy groups and two carbons in heterocyclic ring of piperidin-4-one, respectively. The signal at $\delta$ 184.27 was due to the presence of carbon in the carbonyl group and the signal at $\delta 160.92$ was due to the presence of an oxy-aryl carbon. Then, the signals at $\delta 137.83-114.99$ were due to the presence of aromatic carbons in a benzenesulfonyl and two 4-methoxyphenyl rings of compound 2 .

The Gaussian calculation is come out with the geometry for energy optimization values for the ligand is $1358 \mathrm{Ha}$. Base on this calculation, it seem that it is supported with our hyphothesis that the (E) configuration is more stable than (Z) configuration.

The molecular docking study was performed to predict the potency of compound $\mathbf{2}$ as inhibitor for dengue virus NS2B/NS3 protease. Based on docking results, it seem that compound $\mathbf{2}$ is active against DEN2 NS2B/NS3. Hydrogen bonding was performed between ligand and one of the catalytic triad (i.e. His51) (Table I). van der Waals interaction was also established between ligand and Gly151 and $\pi$ interaction with the residue Pro132 (Table I). In addition, this compound also has hydrophobic interaction with Arg54 (Table I). The spatial arrangement of the compound $\mathbf{2}$ is depicted in (Figure 4) and panduratin A was used as positive control. it has been docked previously (Frimayanti et al., 2011).

MD simulation was also performed to panduratin A as a positive control and compound 2. The interaction between ligand and receptor is still maintain to have hydrogen bonding with His51 residue, and amazingly that the other catalytic triad such as Asp75 and Ser135 were also showed interactions with the ligand. MD simulation is carried out on this ligand to further explore the interaction between ligand and receptor (Adam et al., 2015). The properties of this complex was inspected to check the stability of MD. In this study, the MD simulations were performed at temperature of $300^{\circ} \mathrm{K}$ to check the affinity of the ligand to the binding site. 
Adel Zamri

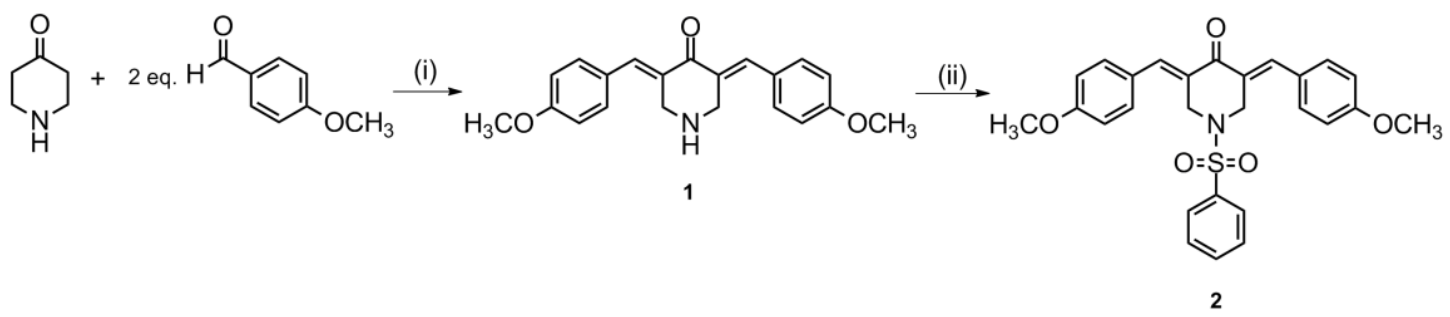

Figure 1. Synthesis of compound 2 under reflux, (i) $\mathrm{KOH}$, EtOH, (ii) $\mathrm{PhSO}_{2} \mathrm{Cl}_{,} \mathrm{Cs}_{2} \mathrm{CO}_{3}, \mathrm{CH}_{3} \mathrm{CN}$.

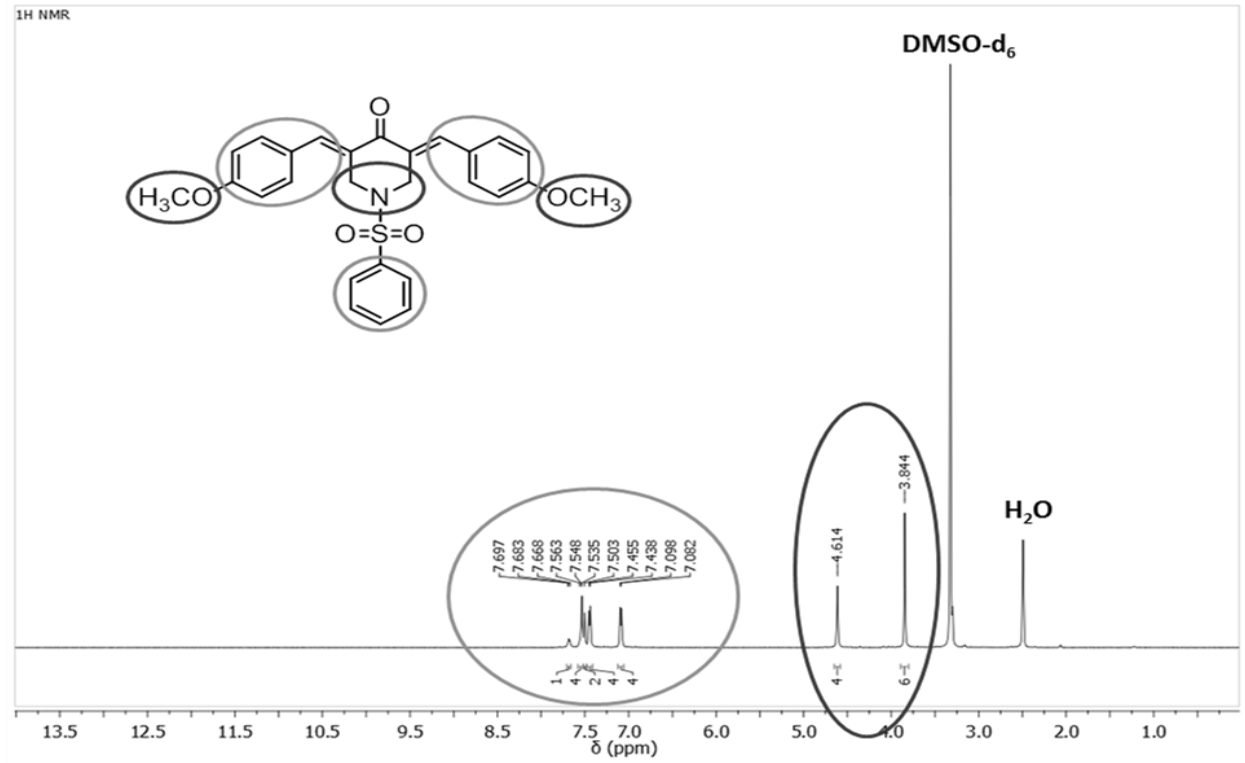

Figure 2. ${ }^{1} \mathrm{H}$ NMR spectra of compound 2

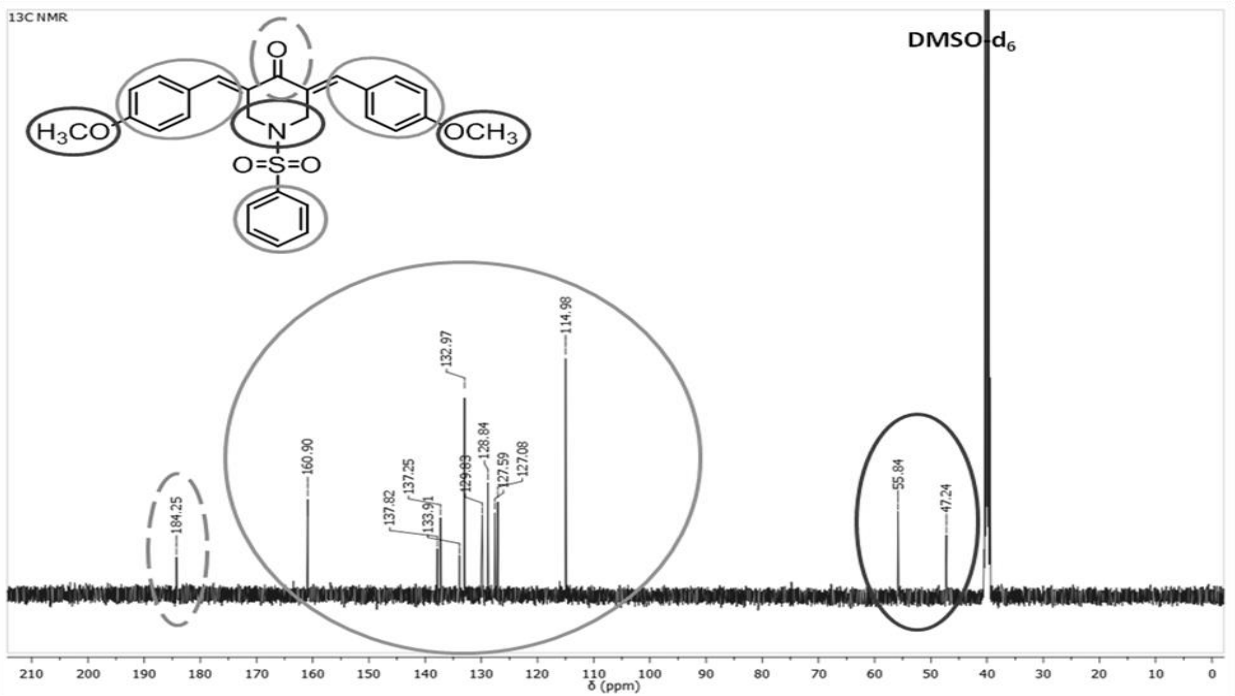

Figure $3 .{ }^{13} \mathrm{C}$ NMR spectra of compound 2

Volume 30 Issue 2 (2019)

87 
Table I. Docking output

\begin{tabular}{ccccc}
\hline \multirow{2}{*}{ Compounds } & \multicolumn{3}{c}{ Interactions } \\
\cline { 2 - 5 } & van der Waals & Hydrophobic & त-Interaction & Hydrogen Bonding \\
\hline Panduratin A & His51; Pro132 & - & - & His51; Gly153 \\
Compound 2 & Gly51 & Arg54 & Pro132 & His51 \\
\hline
\end{tabular}

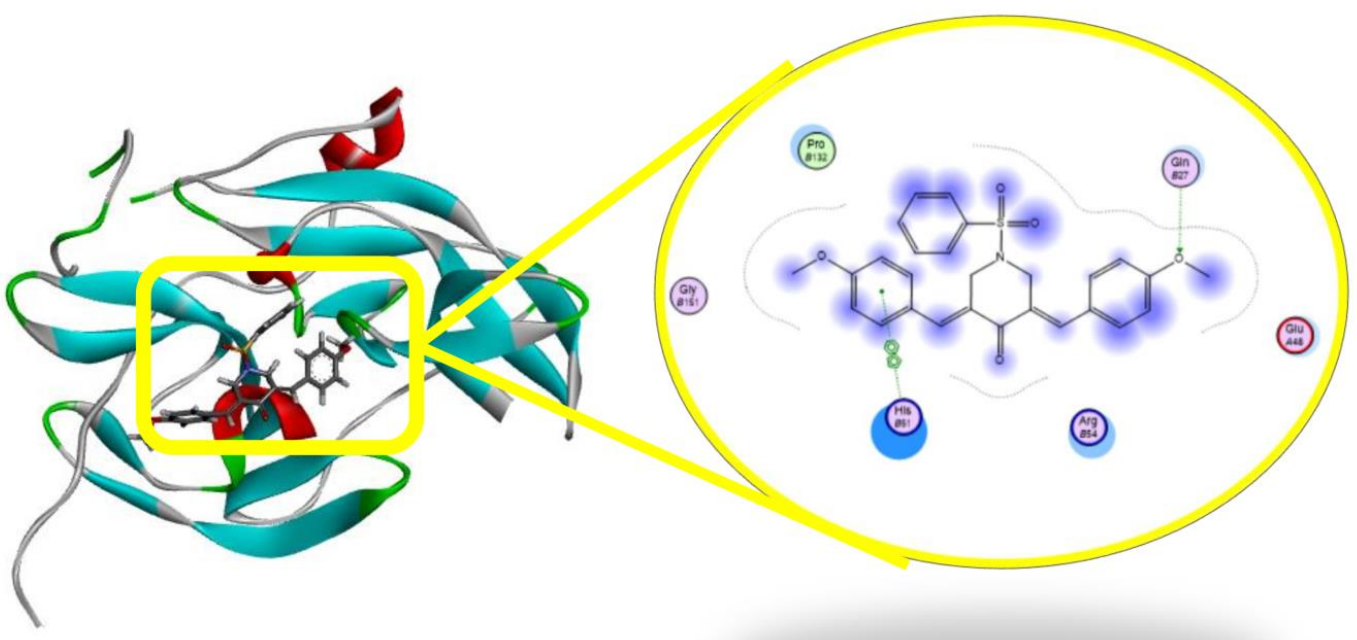

Figure 4. Spatial arrangement of the compound 2

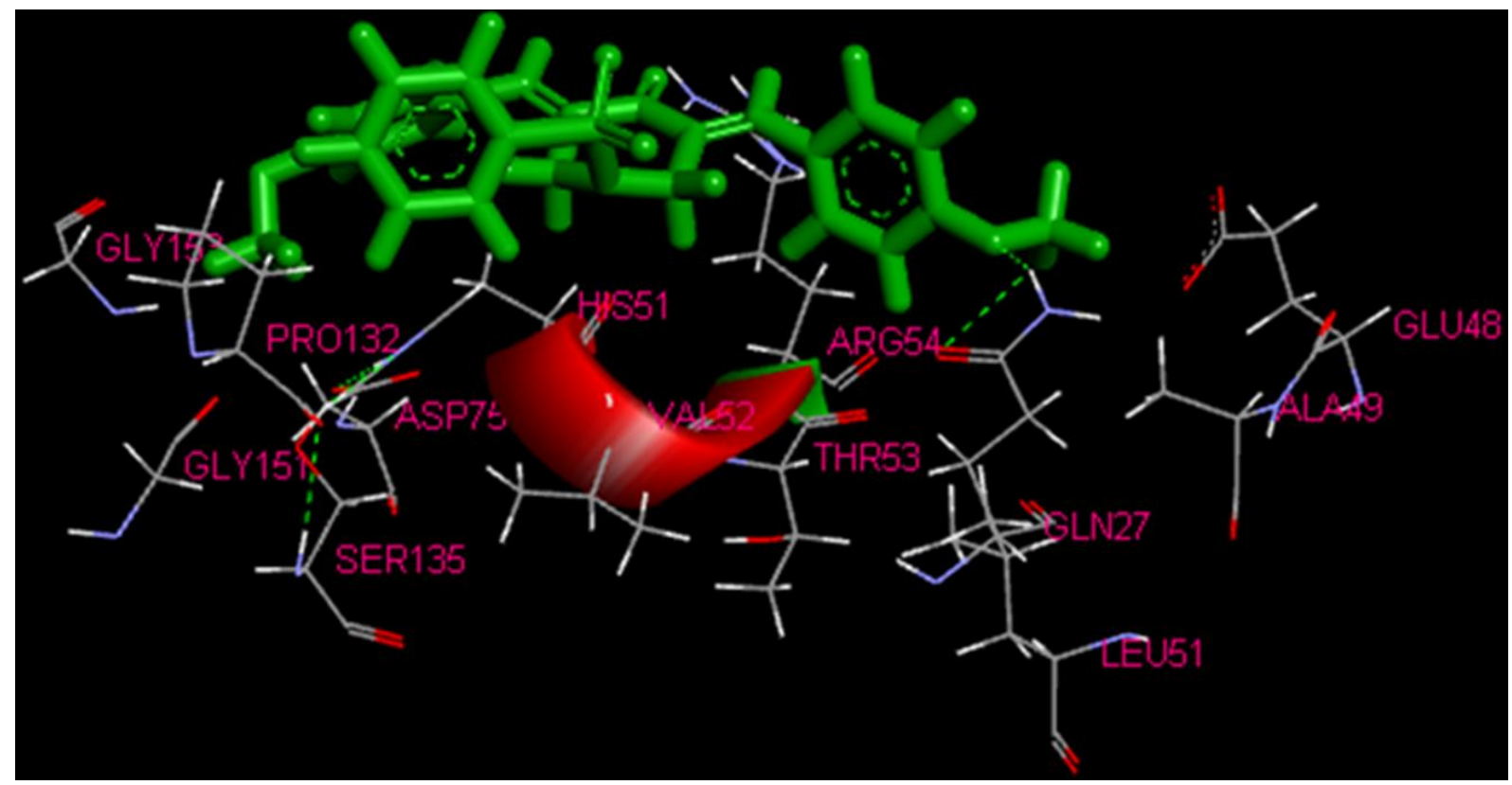

Figure 5. Visualization of MD simulation of compound 2 
Generally, this ligand are maintaned to binding with the active site and essential residues such as His51, Asp75, Ser135, Pro132 and Gly151 (Frimayanti et al., 2011).

Table II. The binding free energy from the MD simulation

\begin{tabular}{lc}
\hline Compounds & $\begin{array}{c}\text { Binding free energy } \\
\text { (kcal/mol) }\end{array}$ \\
\hline Panduratin A & -59.78 \\
Compound 2 & -61.01 \\
\hline
\end{tabular}

The MD simulation results are shown that the range of binding free energy betwen ligand and panduratin A was not too large (Table II). After the MD simulation, the ligand was maintained to interact with the same residues (Figure 5)., it is presumably that compound $\mathbf{2}$ showed very good activity against DEN2 NS2B/NS3 and can be developed as a new inhibitor for dengue.

\section{CONCLUSION}

A benzenesulfonyl curcumin analogue has been synthesized via two steps reaction. All the spectroscopic data agreed with the structure of product that was expected. The in silico studies showed that compound $\mathbf{2}$ was able to maintain the hydrogen bonding with the active site residue such as His51, Asp75 and Ser135, in addition, this compound also has the range of the binding free energy is so close with the panduratin A (i.e. positive control). It is presumably that this compound showed very good activity against DEN2 and can be developed as a new inhibitor for dengue DEN2 NS2B/NS3.

\section{ACKNOWLEDGEMENT}

This work has been funded by DPRM KEMENRISTEK DIKTI through PDUPT grant with contract number of 291/UN.19.5.1.3/PP/ 2018.

\section{REFERENCES}

Adam H., Josep RG., Modesto O. and Josep LG. 2015. Molecular dynamic simulations: advances and application. Adv. Appl. Bioinform. Chem. 8: 37-47.

Chambers TJ., Nestorowicz A., Amberg SM. and Rice CM. 1993. Mutagenesis of the yellow fever virus NS2B protein: effects on proteolytic processing, NS2B-NS3 complex formation, and viral replication. J Virol. 67(11): 6797807.
Eryanti Y., Herlina T., Zamri A., Halim SNAH, Shiono Y., Syah YM. and Supratman U. 2014. 3.5Bis(2-hydroxybenzylidene) piperidin-4one. Molbank. 2014(2): M825. doi: 10.3390/M825.

Falgout B., Pethel M., Zhang Y. and Lai C. 1991. Both non structural proteins NS2B and NS3 are required for the proteolytic processing of dengue virus non structural protein. J Virol. 65(5): 2467-75.

Frimayanti N., Chee CF., Zain SM. and Rahman NA. 2011. Design of new competitive dengue NS2B/NS3 protease inhibitors - a computational approach. Int J Mol Sci. 12(12): 1089-100. doi: 10.3390/ijms12021089.

Guzman MG., Halstead SB., Artsob H., Buchy P., Farrar J. and Gubler DJ. 2010. Dengue: a continuing global threat. Nat Rev Microbiol., 8(12 Suppl): S7-16. doi: 10.1038/nrmicro2460.

Humphrey W., Dalke A. and Schulten K. 1996. VMD: visual molecular dynamics. Journal of Molecular Graphics. 14(1): 33-8. doi: 10.1016/0263-7855(96)00018-5.

Jasril J., Ikhtiarudin I., Zamri A., Teruna HY. and Frimayanti N. 2017. New fluorinated chalcone and pyrazoline analogs: synthesis, docking and molecular dynamic studies as anti cancer agents. Thai Journal of Pharmaceutical Sciences. 41(3): 1-6.

Kumar B., Singh V., Shankar R., Kumar K. and Rawal RK. 2017. Synthetic and medicinal properties of structurally modified curcumin. Curr Top Med Chem. 17(2): 148161. doi: 10.2174/1568026616666160 605050052

Mathew D., Hsu W-L. 2018. Antiviral potential of curcumin. Journal of functional foods. 40: 692-9. doi: 10.1016/j.jff.2017.12.017.

Morens D. and Fauci A. 2008. Dengue and hemorrhagic fever: a potential threat to public health in United States. J Am Med Assoc. 299(2): 214-6. doi: 10.1001/jama.2007.31-a.

Nelson MT., Humphrey W., Gursoy A., Dalke A., Kalé LV., Skeel RD. and Schulten K. 1996. NAMD: a parallel, object-oriented molecular dynamics program. The International Journal of High Performance Computing Application. 10(4): 251-68. doi: $10.1177 / 109434209601000401$

Padilla-S L., Rodriguez A., Gonzales MM., Gallego-G JC. and Castaño-O JC. 2014. Inhibitory 
effects of curcumin on dengue virus type 2infected cells in vitro. Arch Virol. 159(3): 573-9. doi: 10.1007/s00705-013-1849-6.

Powers CN. and Setzer WN. 2016. An in-silico investigation of phytochemicals as antiviral agents dengue fever. Com Chem High Throughput screen. 19(7): 516-36. doi: $\quad 10.2174 / 138620731966616050612$ 3715.

Sampath A. and Padmanabhan R. 2009. Molecular targets for flavivirus drug discovery. Antivir Res. 81(1): 6-15. doi: 10.1016/j.antiviral.2008.08.004. 